\title{
PRODUÇÃO DE CELULASE E AMILASE POR ACTINOBACTÉRIAS DO SEMIÁRIDO BRASILEIRO
}

Daislany Andreia da Silva Alves"; Valéria Maria Araújo Silva2; Frederico Alekhine Chaves Garcia²; Suzana Cláudia Silveira Martins ${ }^{3}$; Claudia Miranda Martins ${ }^{3}$.

1 Graduada em Ciências Biológicas - Bacharelado, Departamento de Biologia da Universidade Federal do Ceará.

2 Estudante do Programa de Pós-Graduação em Ecologia e Recursos Naturais, Departamento de Biologia da Universidade Federal do Ceará.

3 Professora Doutora do Departamento de Biologia da Universidade Federal do

Ceará (claudia.miranda.martins@gmail.com) Fortaleza-Brasil.

Recebido em: 03/10/2016 - Aprovado em: 21/11/2016 - Publicado em: 05/12/2016 DOI: 10.18677/EnciBio_2016B_121

\section{RESUMO}

Os solos constituem a base de todos os ecossistemas terrestres abrigando uma grande diversidade de organismos que são vitais para manutenção de suas características biológicas. Fazendo parte deste ambiente diverso encontram-se as actinobactérias, um grupo microbiano que desempenha funções ecológicas importantes, como a reciclagem dos substratos orgânicos celulose e o amido, de elevada complexidade química e ampla disponibilidade no solo. Tendo em vista a importância ecológica e biotecnológica dessas enzimas, este trabalho objetivou avaliar a atividade amilolítica e celulolítica de 39 cepas de actinobactérias provenientes de amostras de solo de região semiárida, localizada no Perímetro Irrigado Baixo Acaraú (PIBAU) no município de Marco, Estado do Ceará. A atividade enzimática foi determinada pelo método da difusão em meio ágar específico com posterior mensuração em milímetros do halo de hidrólise de cada substrato e sua respectiva colônia. O Índice Enzimático foi determinado pela razão entre os respectivos halos de hidrólise. Dentre as 39 cepas avaliadas, 30 (76,92\%) apresentaram produção de celulase, com destaque para a cepa BA-3 que apresentou o maior índice celulolítico (3,33), enquanto que 36 (92,3\%) foram amilase positiva, apresentando índice amilolítico de até 6,02 (BA-8). Esses resultados demonstram a potencialidade enzimática de actinobactérias de ambientes semiáridos e apontam para sua utilização como ferramentas biotecnológicas na restauração de ambientes naturais degradados.

PALAVRAS-CHAVE: Bactérias. Caatinga.Enzimas

\section{PRODUCTION CELLULASE AND AMYLASE OF ACTINOBACTERIA FROM BRAZILIAN SEMIARID}

\begin{abstract}
Soils are the basis of all terrestrial ecosystems housing a wide diversity of organisms that have vital role in maintaining their biological characteristics. As part of this diverse environment are the actinobcteria, a microbial group that have important ecological functions such as recycling of organic compounds cellulose and starch of high chemical complexity and wide availability in soil. In view of the biological and
\end{abstract}


biotechnological importance of these enzymes, this study aimed to evaluate the amylolytic and cellulolytic activity 39 actinobacteria strains from semiarid region of soil samples located in the Irrigated Perimeter Low Acaraú (PIBAU) in the municipality of Marco, State of Ceara. The production of enzymes was detected by the enzymatic diffusion in specific agar medium and with later measurement of halo of degradation of substrate and its respective colony. Enzimatyc Index was calculated by the rate between the respective halo of hydrolysis. Among the 39 strains evaluated, $30(76.92 \%)$ presented production of cellulase, especially the BA-3 strain which showed the highest cellulolytic index (3.33), while 36 (92.3\%) were positive amylase, with amylolytic index of 6.02 (BA-8). These results indicate the enzymatic potential of actinobacteria from the semiarid region analised and point to their use as biotechnological tools in the recovery of degraded natural environments.

Keywords: Enzymes. Bacteria. Caatinga.

\section{INTRODUÇÃO}

Os solos constituem a base de todos os ecossistemas terrestres abrigando uma grande diversidade de organismos, como insetos, anelídeos, plantas, animais, e micro-organismos. Esses últimos desempenham funções relevantes para o ecossistema, como a ciclagem de elementos essenciais ( $\mathrm{C}, \mathrm{N}$ e $\mathrm{P}$ ) (BALDOTTO \& BALDOTTO, 2014). Entre os micro-organismos presentes no solo, destacam-se as actinobactérias que, em função da abundância e diversidade, são importantes sob os aspectos ecológicos e biotecnológicos.

As actinobactérias compõem um grupo bacteriano com características morfológicas, fisiológicas e ecológicas diversas e que habitam pincipalmente o solo (ADEGBOYE \& BABALOLA, 2012; MANSOUR et al., 2015). No entanto, também foram reportadas em regiões de mangue (KAFILZADEH \& DEHDARI, 2015), ambientes marinhos (SUBRAMAN \& AALBERSBERG, 2012) e de água doce (GEBREYOHANNES et al., 2013), assim como em lugares extremamente secos (MOHAMMADIPANAH \& WINK, 2016) ou de baixas temperaturas (LEARN-HAN et al., 2012). Essas bactérias desempenham papel vital na solubilização de compostos orgânicos, contribuindo dessa forma, para a reposição de nutrientes essenciais (MABROUK \& SALEH, 2014). São bactérias Gram-positivas com elevada concentração de guanina e citosina no genoma e que apresentam a formação de filamentos ramificados ou hifas e esporos assexuais (LEARN-HAN et al., 2012; SHARMA, 2014). Sua estrutura morfológica que as assemelha aos fungos filamentosos constitui um possível mecanismo adaptativo do grupo (SHARMA, 2014), possibilitando adaptar-se a diferentes ambientes, como solos com reduzida disponibilidade de água (LEBLANC et al., 2008), o que é característico de regiões semiáridas.

Os solos de áreas semiáridas apresentam reduzida oferta de substâncias nutritivas e condições abióticas restritivas (KÖBERL et al., 2011), o que representa um fator limitante para o estabelecimento de diversas espécies biológicas. No entanto, apesar do clima e fatores ecológicos como a oferta de água, $\mathrm{pH}$ e compostos orgânicos influenciarem negativamente 0 desenvolvimento de populações microbianas neste tipo de hábitat (VAN HOP et al., 2011).

Apesar de diversos estudos com este grupo microbiano se concentrarem na síntese de metabólitos secundários com ação antibiótica (DURAIPANDIYAN et al., 2010; PRIYADHARSINI \& DHANASEKARAN, 2015), algumas pesquisas revelam o potencial destas bactérias na síntese de enzimas hidrolíticas extracelulares, dentre as quais se sobressaem as celulolíticas e amilolíticas (SILVA et al., 2012; SAKURE 
et al., 2015; SILVA et al., 2015b). Estas enzimas estão envolvidas em mecanismos de mineralização de nutrientes, assim como também em processos de degradação de moléculas de difícil solubilização presentes no solo (BURNS et al., 2013), sendo, portanto, importantes na sustentabilidade de ecossistemas, o que reforça o potencial ecológico desses micro-organismos.

Embora a celulose e o amido constituam a maior parte da biomassa vegetal, estes representam polissacarídeos de difícil degradação. Dessa forma, a presença de enzimas microbianas extracelulares capazes de degradar biopolímeros de estrutura complexa como os referidos carboidratos, torna-se relevante para reposição de nutrientes fundamentais no ecossistema (IRFAN et al., 2012; BALDRIAN, 2014). Dessa forma, a incorporação de micro-organismos capazes de decompor compostos naturais complexos caracteriza-se como uma ferramenta auxiliar a restauração de sistemas ecológicos degradados (BALAMURUGAN et al., 2011).

Diante do apresentado, o presente estudo objetivou caracterizar cepas de actinobactérias naturais de uma região semiárida brasileira, quanto às atividades celulolítica e amilolítica.

\section{Caracterização da área}

\section{MATERIAL E MÉTODOS}

A região de coleta faz parte da Fazenda Lote T6/4 Duvalle Frutas lote T4 (37'26" S, 408'48" W) que pertence ao Perímetro I rrigado Baixo Acaraú (PIBAU) no município de Marco, Estado do Ceará. Os solos característicos da região são do tipo aluvial, litolíticos, planossolo solódico, podzólico vermelho-amarelo e solonetz solodizado. A vegetação classifica-se como caatinga arbustiva densa e aberta, apresentando também uma estrutura vegetacional de faixa litorânea e floresta mista dicotilo-palmácea, com clima característico do tipo tropical quente semiárido e temperaturas médias entre $2^{\circ} \mathrm{C}$ a $28^{\circ} \mathrm{C}$ (IPECE, 2015) .

\section{Coleta do solo}

As amostras de solo superior $(0-10 \mathrm{~cm})$ foram coletadas no primeiro semestre de 2015, no mês de abril no término da estação apontada como de maior pluviosidade. Para cada local foram dispostos casualmente cinco quadrantes de 25 $\mathrm{m}^{2}$ (5 $\mathrm{m} \times 5 \mathrm{~m}$ ), considerando um espaço mínimo de $10 \mathrm{~m}$ entre cada. De cada bloco foram coletadas cinco amostras compostas de solo. A seleção dos blocos ocorreu aleatoriamente através de sorteio. As amostras obtidas foram acomodadas em embalagens plásticas identificadas, armazenadas em recipientes de isopor refrigeradas e direcionadas ao Laboratório de Microbiologia Ambiental (LAMAB) do Departamento de Biologia da Universidade Federal do Ceará - UFC.

\section{Micro-organismos}

Um total 39 cepas de actinobactérias isoladas e descritas culturalmente por SILVA et al. (2015a) foram utilizadas na presente pesquisa. Estas cepas estão codificadas como "BA", indicativo de Baixo Acaraú e numeradas em ordem crescente (BA-1, BA-2, BA-3, BA-4 até BA-39), e fazem parte da coleção de actinobactérias de ambientes semiáridos do Ceará sendo mantidas numa temperatura de 4ํㅡ em meio Caseína Dextrose Ágar (CDA) camada alta no Laboratório de Microbiologia Ambiental (LAMAB) do Departamento de Biologia da Universidade Federal do Ceará. 


\section{Atividade celulolítica}

As actinobactérias foram testadas quanto a sua capacidade de crescer e hidrolisar compostos celulolíticos em meio acrescido com carboximetilcelulose (FLORÊNCIO et al., 2012) com a seguinte composição em (g.L-1): $\mathrm{MgSO}_{4}(0,05 \mathrm{~g})$, $\mathrm{KCl}(0,5 \mathrm{~g}), \mathrm{NaNO}_{3}(3,0 \mathrm{~g}), \mathrm{FeSO}_{4} .7 \mathrm{H}_{2} \mathrm{O}(0,01 \mathrm{~g}), \mathrm{K}_{2} \mathrm{HPO}_{4}(1,0 \mathrm{~g})$, Agar $(15,0 \mathrm{~g})$, Caborximetilcelulose sal sódico $(5,0 \mathrm{~g})$ em pH 6,0. A carboximetilcelulose (CMC) foi acrescentada neste meio como a única fonte de carbono e energia. As cepas foram inoculadas em forma de spot em quadruplicata, com dois ensaios independentes. Após a inoculação, as placas foram incubadas em B.O.D a uma temperatura de $28^{\circ} \mathrm{C} \pm 2$ durante 10 dias. Em seguida uma alíquota de $10 \mathrm{~mL}$ de vermelho congo $\left(1 \mathrm{~g} \cdot \mathrm{L}^{-1}\right)$ foi adicionada em cada placa deixando-se reagir por 15 minutos em temperatura ambiente $\left(25^{\circ} \mathrm{C}\right)$. Depois deste intervalo, o excesso da solução foi descartado e $10 \mathrm{~mL}$ de $\mathrm{NaCl}(1 \mathrm{M})$ foram adicionados em cada placa, deixando-se reagir por 30 minutos em temperatura ambiente $\left(25^{\circ} \mathrm{C}\right)$. Após o descarte da solução salina, foi observada a presença de áreas de hidrólise em volta das colônias, os quais foram indicativos de atividade celulolítica. As medidas dos diâmetros dos halos de hidrólise e das respectivas colônias foram efetuadas utilizando-se um paquímetro digital e expressas em milímetros (mm) (GUPTA et al., 2011; CHARBONNEAU et al., 2012).

\section{Atividade amilolítica}

A capacidade de crescer e sintetizar amilases foi observada pela inoculação das actinobactérias no meio de cultura Ágar amido com a seguinte composição em em g. $L^{-1}:$ peptona $(10,0)$ extrato de carne $(3,0)$, amido solúvel $(5,0), \mathrm{NaCl}(5,0)$ e ágar $(20,0)$. O pH da solução foi ajustado entre 6,8 e 7,2 (SALAHUDDIN et al., 2011). As cepas foram então inoculadas em forma de spot em quadruplicata, seguida de dois ensaios independentes.

Após a inoculação, as placas foram incubadas a $28^{\circ} \mathrm{C} \pm 2$ na B.O.D. por um período de 10 dias. Após este ínterim, foi efetuada a revelação das zonas de hidrólise com adição de uma alíquota de $10 \mathrm{~mL}$ de tintura de iodo, composta de $1 \mathrm{~g}$ de iodo e $2 \mathrm{~g}$ de iodeto de potássio para cada $300 \mathrm{~mL}$ de água destilada, na superfície do meio contendo as colônias. Regiões claras em volta da colônia foi o critério utilizado para atividade amilolítica positiva. As medidas dos diâmetros dos halos e das respectivas colônias foram feitas utilizando um paquímetro digital e 0 resultado expressa em milímetros (mm) (SALAHUDDIN et al., 2011).

\section{Índice Enzimático}

O Índice Enzimático (IE) foi calculado através relação entre os diâmetros do halo de degradação hidrolítica e das respectivas colônias utilizando-se a seguinte equação: $\mathrm{IE}=\mathrm{Dh} / \mathrm{Dc}$. Sendo Dh o diâmetro em milímetros $(\mathrm{mm})$ do halo de hidrólise e Dc o diâmetro em mm da colônia de actinobactérias (FLORÊNCIO et al., 2012).

\section{Análise estatística}

Os índices celulolíticos e amilolítico foram determinados a partir dos testes de atividade enzimática, os quais foram realizados em quadruplicata com dois ensaios independentes. Esses dados foram preliminarmente submetidos ao teste de normalidade Shapiro-Wilk a $5 \%$ de probabilidade. Em caso de distribuição normal foi aplicado o teste ANOVA e, em caso negativo, foi aplicado o teste estatístico não paramétrico Kruskal-Wall, usando o software GraphPad Prism 5.00 (GraphPad 
Software*, San Diego, CA). As médias significativamente diferentes foram comparadas através do teste de Scott-Knott $(p<0,05)$.

\section{RESULTADOS E DISCUSSÃO}

\section{Atividade Celulolítica}

O halo indicador da atividade celulolítica foi verificado em $30(76,92 \%)$ das cepas de actinobactérias. A ausência de zonas de degradação nas cepas (BA-2, BA-5, BA-7, BA-8, BA-9, BA-12, BA-19, BA-28, BA-29) foi indicativa da incapacidade de síntese de celulase. A análise estatística demonstrou diferença significativa $(p<0,05)$, entre os valores dos índices enzimáticos das cepas produtoras de celulase, destacando-se as cepas BA-3 e BA-24, com valores significativamente superiores as demais. Referido parâmetro variou entre 1,09 (BA-1) a 3,33 (BA-3), o que indica a importância dessas bactérias na decomposição da celulose, como pode ser verificado na figura 1.

As actinobactérias são reconhecidas pelo seu potencial enzimático, sobretudo, com relação à síntese de enzimas celulolíticas (EL-SERSEY et al., 2010; HENG \& HAMZAH, 2014). Estudo de SILVA et al. (2015b) com actinobactérias de outra região do semiárido do nordeste brasileiro confirmou esse potencial, sendo registrados índices enzimáticos com valores acima de 6,0, aproximadamente duas vezes maior que o detectado no presente estudo. Referida diferença reforça a importância de estudos com esse grupo de bactérias em diferentes regiões do semiárido do Brasil.

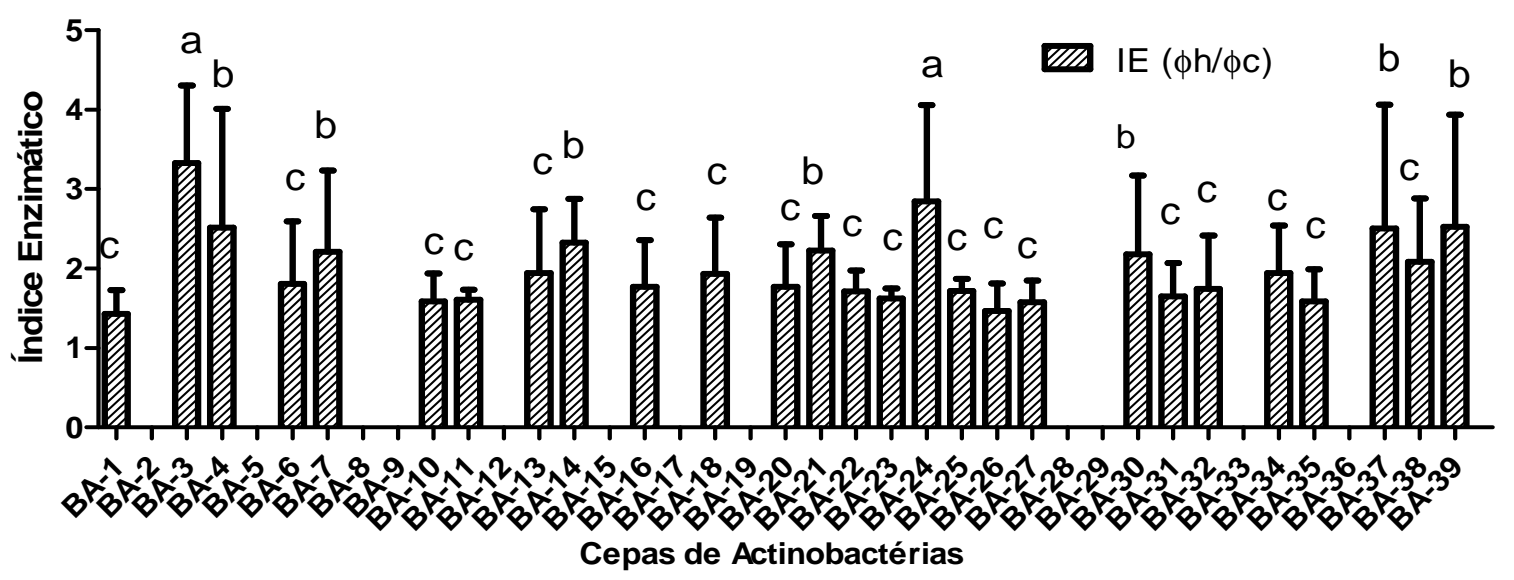

FIGURA 1. Índice celulolítico de actinobactérias nativas do solo do Perímetro Irrigado do Baixo Acaraú, no Ceará. Médias seguidas pela mesma letra não diferem entre si pelo teste de Scott-Knott ao nível de 5\% de

Como estudos com actinobactérias oriundas do semiárido do nordeste brasileiro, particularmente do bioma Caatinga, ainda são escassos, o presente estudo comparou os resultados da atividade enzimática com trabalhos realizados com actinobactérias de outros habitats. Assim, MOHANTA (2014) ao analisar a atividade celulolítica de actinobactérias provenientes de solos de regiões de mangue na Índia, constatou que 18\% (9) das cepas avaliadas apresentaram produção de celulases. SAKURE et al. (2015) registraram positividade em $80 \%$ das cepas estudadas, as quais foram isoladas da região rizosférica de plantas medicinais, também na Índia. Esses dados sugerem a influência do habitat na síntese de 
enzimas celulolíticas, assim como o potencial de adaptação e colonização das actinobactérias a diferentes ecossistemas.

Uma vez que a síntese anual de celulose pelas plantas pode chegar a $4 \times 10^{9}$ toneladas (IRFAN et al., 2012) e que as celulases desempenham importante papel na reciclagem desse polímero (MAKOI \& NDAKIDEMI, 2008), a presença de microorganismos capazes de degradar referido substrato é importante para disponibilizar compostos mais simples que possam ser assimilados por outros organismos (BALDRIAN, 2014). Esse processo contribui decisivamente para ciclagem de nutrientes, principalmente em regiões de condições climáticas limitantes. Assim, é possível deduzir que as cepas do presente estudo, ao participarem da degradação de materiais celulolíticos também contribuem para a diversidade microbiana do solo (BALDRIAN, 2014).

O crescimento e sobrevivência de micro-organismos em solos cultiváveis dependem, entre outros fatores, da obtenção de carbono, sendo a celulose a principal fonte disponível desse elemento (MAKOI \& NDAKIDEMI, 2008). Assim, as actinobactérias do presente estudo, isoladas de solo de região semiárida de uso para agricultura, podem ser consideradas engenheiros ecossistêmicos, pela capacidade de viabilizar componentes orgânicos fundamentais para diversas formas de vida a partir de substratos celulósicos complexos.

Com base nos critérios propostos por SILVA et al. (2015b), 23,07\% as cepas de actinobactérias analisadas no vigente estudo foram classificadas como fortemente produtoras de celulase (BA-3, BA-4, BA-7, BA-14, BA-21, BA-24, BA-30, BA-37, BA-38, BA-39), apresentando IE $\geq 2$ (Figura 2). As cepas BA-03 e BA-24 apresentaram, nesta ordem, os maiores valores de IEs de 3,33 e 2,84 (Figura 1). Aproximadamente $41 \%$ das cepas de actinobactérias apresentaram $1,5 \leq \mathrm{IE}<2$ sendo por isso consideradas moderadamente produtoras (BA-6, BA-10, BA-11, BA-13, BA16, BA-18, BA-20, BA-22, BA-23, BA-25, BA-27, BA-31, BA-32, BA-34, BA-35, BA36) e apenas $12,82 \%$ das cepas apresentaram $1 \leq \mathrm{IE}<1,5$, sendo classificadas como fracamente produtoras (BA-1, BA-15, BA-17, BA-26, BA-33) (Figura 2). Esses resultados reforçam 0 potencial celulolítico de actinobactérias de ambientes semiáridos, conforme destacado por SILVA et al. (2015b), para cepas oriundas da região rizosférica de leguminosas do Parque Nacional de Ubajara-CE.

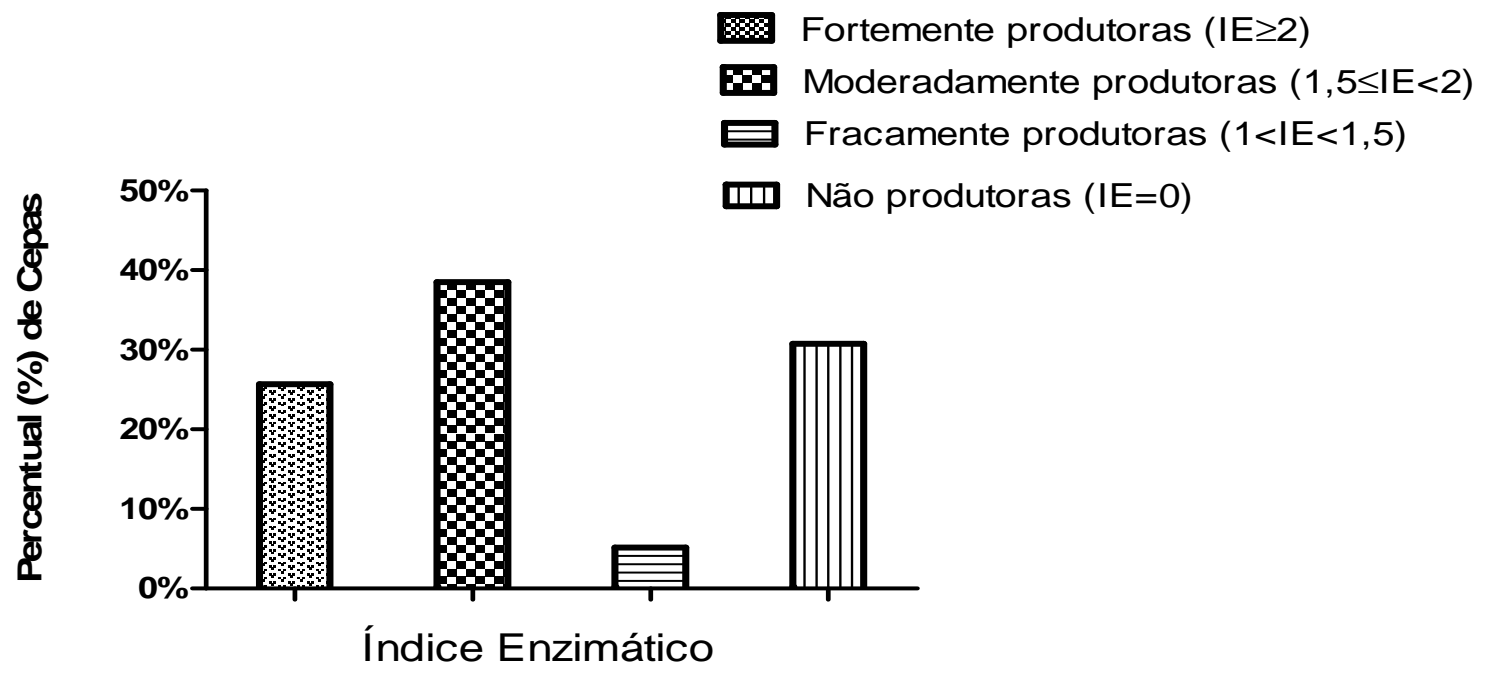

FIGURA 2. Categorização das cepas de actinobactérias nativas do solo do Perímetro Irrigado do Baixo Acaraú, no Ceará, quanto ao índice celulolítico. 
Visto que a degradação de detritos vegetais incorporados no solo depende da ação de enzimas celulolíticas (MAKOI \& NDAKIDEMI, 2008) as cepas da presente pesquisa, desempenham importante papel para manutenção de características biológicas e produtivas nos solos da região analisada.

\section{Atividade Amilolítica}

O halo indicador da degradação do amido foi observado em $36(92,3 \%)$ das cepas analisadas, enquanto que somente $7,7 \%$ não apresentaram zonas características de ação enzimática (BA-2, BA-5, BA-9). O percentual de positividade foi ainda mais elevado, que o valor de $82 \%$ reportado por SILVA et al. (2015b) para cepas de actinobactérias provenientes de região semiárida localizada em Ubajara, Ceará. Esses valores percentuais mostram o potencial de actinobactérias do semiárido para síntese da enzima amilase e destacam a importância de estudos sobre esse grupo bacteriano em regiões do bioma Caatinga.

SALAHUDDIN et al. (2011) e SAKURE et al. (2015) reportaram que a síntese de enzimas atuantes na degradação de substratos complexos é dependente do habitat em estudo. Nesse sentido, SUBRAMAN \& AALBERSBERG (2012) e KAFILZADEH \& DEHDARI (2015), GEBREYOHANNES et al. (2013), MINOTTO et al. (2014) e GEBREYOHANNES (2015) registraram a enzima amilase em actinobactérias nativas de regiões de mangue, ambientes marinhos, rizosfera de tomate na região sul do Brasil (Rio Grande do Sul), bem como em um lago de água doce na Etiópia, respectivamente. Esses trabalhos confirmam a capacidade desse grupo bacteriano para produção da enzima amilase em diferentes ecossistemas e ressalta a importância dessas bactérias na ciclagem de nutrientes, processo vital para a manutenção de sistemas ecológicos naturais.

O índice enzimático das 36 cepas de actinobactérias amilase positiva apresentou significativas variações $(p<0,05)$. A cepa BA-8 destacou-se com o maior $\mathrm{IE}$, correspondendo a 6,02, enquanto a cepa BA-37 apresentou o menor valor de IE $(1,52)$ (Figura 3).

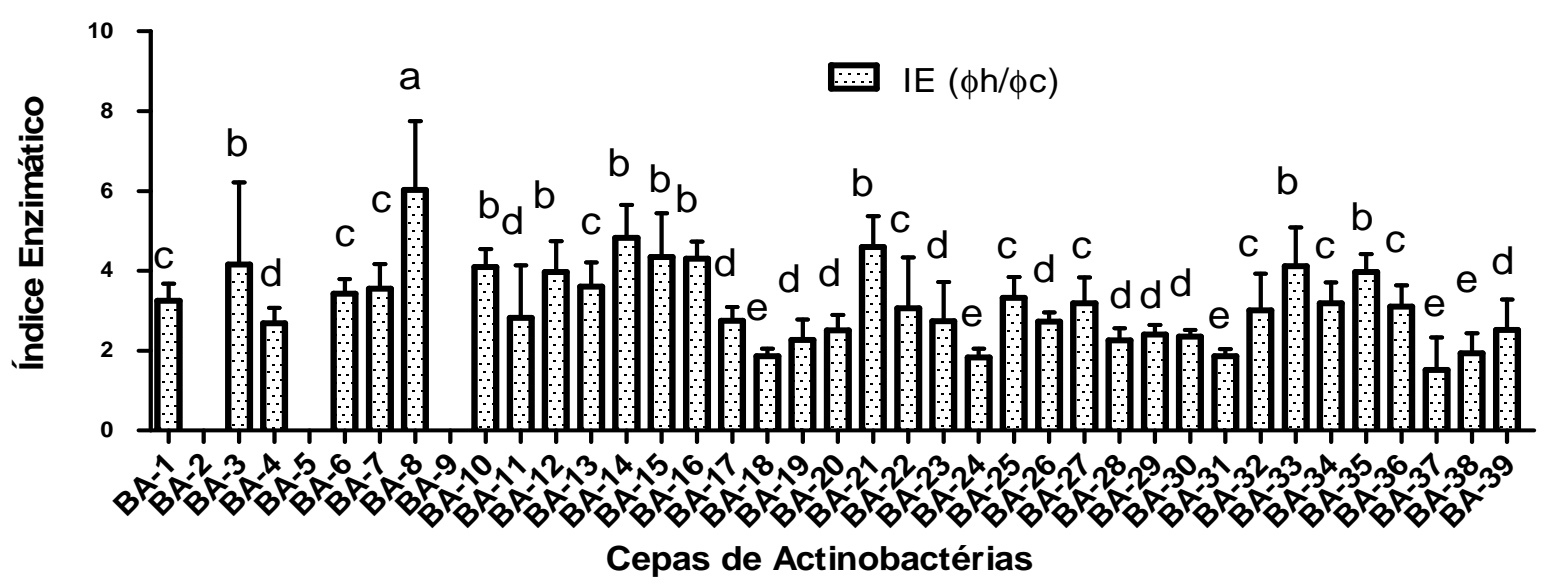

FIGURA 3. Índice amilolítico de actinobactérias nativas do solo do Perímetro Irrigado do Baixo Acaraú, no Ceará. Médias seguidas pela mesma letra não diferem entre si pelo teste de Scott-Knott ao nível de 5\% de probabilidade. 
Aproximadamente $80 \%$ das cepas de actinobactérias (BA-1, BA-3, BA-4, BA6, BA-7, BA-8, BA-10, BA-11, BA-12, BA-13, BA-14, BA-15, BA-16, BA-17, BA-19, BA-20, BA-21, BA-22, BA-23, BA-25, BA26, BA-27, BA-28, BA-29, BA-30, BA-32, BA-33, BA-34, BA-35, BA-36, BA-39), foram classificadas como fortemente produtoras de amilase com IE $\geq 2$, cinco cepas (BA-18, BA-24, BA-31, BA-37, BA-38) (13\%) como moderadamente produtoras ( BA-18, BA-24, BA-31, BA-37, BA-38) com $1,5 \leq \mathrm{IE}<2$. Nenhuma das cepas foi classificada como fracamente produtora $(1 \leq \mathrm{IE}<1,5)$ (Figura 4).

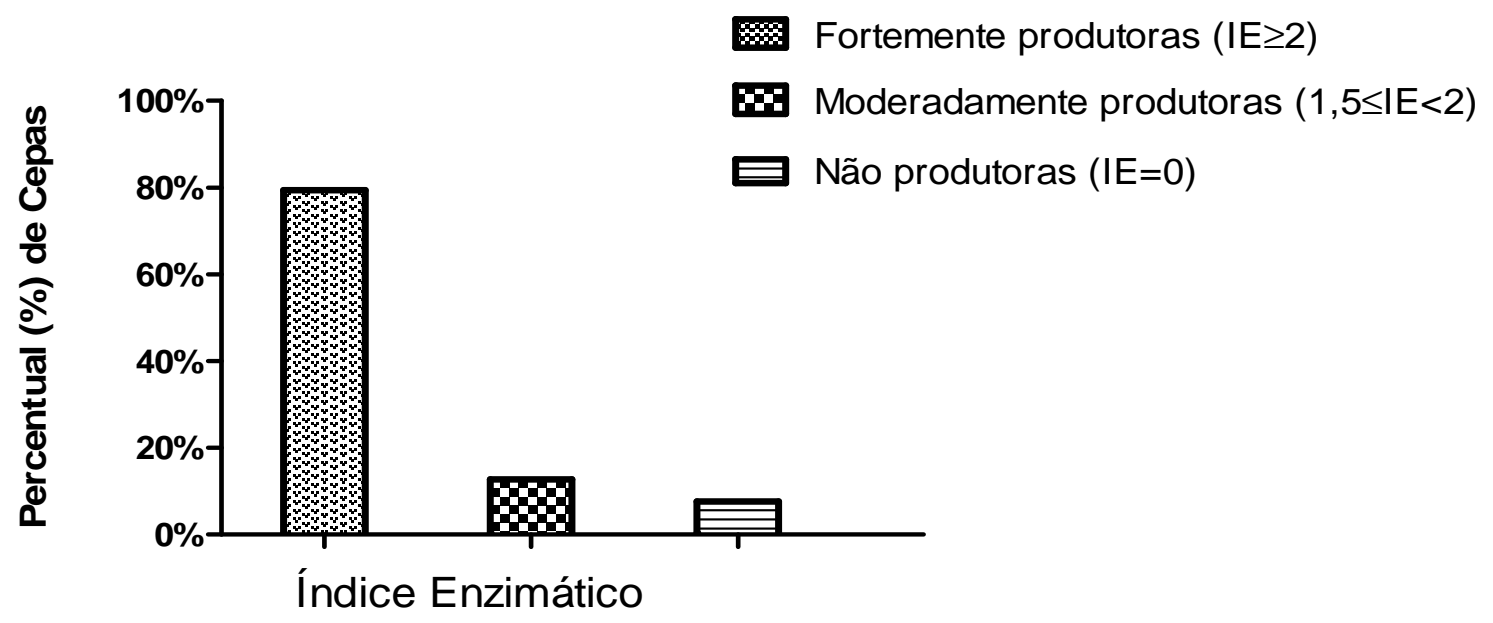

FIGURA 4. Categorização das cepas de actinobactérias nativas do solo do Perímetro Irrigado do Baixo Acaraú, no Ceará, quanto ao índice amilolítico.

SILVA et al. (2015b) demonstraram que de 23 cepas produtoras de amilase, $60 \%$ foram consideradas fortemente produtoras, enquanto que $14 \%$ foram classificadas como moderadamente produtoras. Assim como reportado para actinobactérias celulolíticas, também ainda são poucos os trabalhos avaliando o potencial amilolítico do referido grupo bacteriano na Caatinga (GORLACH-LIRA \& COUTINHO, 2007). Tal fato, embora dificulte a comparação dos resultados do presente estudo, reforçam a importância do mesmo. No entanto, o elevado percentual de actinobactérias amilolíticas também foi registrado por GEBREYOHANNES (2015). Esse autor ao estudar 18 cepas de actinobactérias de solos de regiões da Etiópia constatou a síntese de amilase em $100 \%$ dos isolados, sendo que cerca de $28 \%$ das cepas exibiram máxima atividade amilolítica. Esses resultados confirmam o potencial desse grupo bacteriano na síntese de amilases e reforçam a pertinência de mais estudos que possam avaliar de maneira mais sistêmica a relevância da síntese dessa enzima para solos com características limitantes como aqueles de ambientes semiáridos.

Diversos fatores ecológicos como a oferta de água, pH e o teor de material orgânico no solo, assim como também o clima, acarretam impactos diretos na microbiota dos solos (VAN HOP et al., 2011), implicando em variações na biodiversidade desse ambiente. Desse modo, a presença de grupos microbianos, como as actinobactérias, com ampla e significativa atividade enzimática em ambientes de condições restritivas, ressalta a importância ecológica do referido grupo. De fato, GORLACH-LIRA \& COUTINHO (2007), registraram que a presença de enzimas hidrolíticas extracelulares, como quitinases, celulases, proteases e 
amilases em solos semiáridos, caracterizados pela reduzida oferta de nutrientes, contribuem fortemente no desenvolvimento e sobrevivência de populações microbianas. Além disso, por desempenhar papel fundamental na ciclagem de compostos orgânicos (MAKOI \& NDAKIDEMI, 2008; CRUZ et al., 2013) a diversidade enzimática da microbiota do solo e está intimamente relacionada aos inúmeros processos ecológicos do solo, sendo, portanto, apontada como um notável indício da qualidade do mesmo (KUZYAKOV \& BLAGOTSKAYA, 2015).

\section{CONCLUSÕES}

Cepas de actinobactérias naturais de ambiente semiárido do Baixo Acaraú do Estado do Ceará apresentaram potencial para hidrólise de celulose e amido, constituindo-se assim, elementos importantes para manutenção da diversidade da microbiota do solo.

\section{REFERÊNCIAS}

ADEGBOYE, M. F.; BABALOLA, O. O. Taxonomy and ecology of antibiotic producing Actinomycetes. African Journal of Agricultural Research, v. 7, n. 15, p. 22552261, 2012. Disponível em:< http://www.academicjournals.org/journal/AJAR/articleabstract/03AA96039512>. Doi: 10.5897/AJARX11.071.

BALAMURUGAN, A.; JAYANTHI, R.; NEPOLEAN, P.; VIDHYA, P.R.; PREMKUMAR, $R$. Studies on cellulose degrading bacteria in tea garden soils. African Journal of Plant Sciences, v.5 n.1, p. 22-27, 2011. Disponível em:< www.academicjournals.org/journal/AJPS/article.../EBBB77E2694>.

BALDOTTO, M. A.; BALDOTTO, L. E. B. Ácidos húmicos. Revista Ceres, v. 61, p. 856-881, 2014. Disponível em:< http://dx.doi.org/10.1590/0034737X201461000011>. Doi: 10.1590/0034737X201461000011.

BALDRIAN, P. Distribution of extracellular enzymes in soils: spatial heterogeneity and determining factors at various scales. Soil Science Society of America Journal, $\quad$ v.78, $\quad$ p. 11-18, 2014.Disponível em:< https://dl.sciencesocieties.org/publications/sssaj/abstracts/78/1/11>.

Doi:10.2136/sssaj2013.04.0155dgs.

BURNS, R. G.; DEFOREST, J. L.; MARXSEN, J.; SINSABAUGH, R. L.; STROMBERGER, M. E.; WALLENSTEIN, M. D.; WEINTRAUB, M. N.; ZOPPINI, A. Soil enzymes in a changing environment: Current knowledge and future directions. Soil Biology and Biochemistry, v. 58, p. 216-234, 2013. Disponível em:< http://dx.doi.org/10.1016/j.soilbio.2012.11.009>. Doi: 10.1016/j.soilbio.2012.11.009.

CHARBONNEAU, D. M., MOUELHI, F. M., BOISSINOT, M., SIROIS, M., BEAUREGARD, M. Identification of thermophilic bacterial strains producing thermotolerant hydrolytic enzymes from manure compost. Indian Journal of

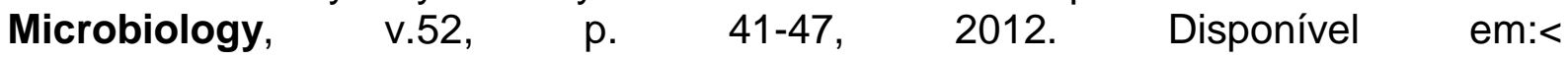
http://www.ncbi.nlm.nih.gov/pmc/articles/PMC3298584/>. Doi: 10.1007/s12088-0110156-8.

CRUZ, R.; LIMA, J.S.; FONSECA, J.C.; FERNANDES, M.J.S.; LIMA, D.M.S.; DUDA, G.P.; MOREIRA, K.A.; MOTTA, C.M.S. Diversity of filamentous fungi of area from 
Brazilian Caatinga and high-level tannase production using mango (Mangifera indica L.) and surinam cherry (Eugenia uniflora L.) leaves under SSF. Advances in Microbiology, v.3, p. 52-60, 2013. Disponível em:< http://www.scirp.org/journal/PaperInformation.aspx?PaperID=41297>.Doi:10.4236/ai m.2013.38A009.

DURAIPANDIYAN, V.; SASI, A. H.; ISLAM, V. I. H.; VALANARASU, M.; IGNACIMUTHU, S. Antimicrobial properties of actinomycetes from the soil of Himalaya. Journal de Micologie Médicale, v.20, p. 15-20, 2010. Disponível em:< https://www.researchgate.net/publication/220000869_Antimicrobial_properties_of_ac tinomycetes_from_the_soil_of_Himalaya>. Doi: 10.1016/j.mycmed.2009.11.002.

EL-SERSEY, N. A.; ABD-ELNABY, H.; ABOU-ELELA, G. M.; IBRAHIM, H. A. H.; ELTOUKHY, N. M. K. African Journal of Biotechnology, v.9, n.38, p. 6355-6364, 2010. Disponível em: www.academicjournals.org/.../article1380698170_ElSersy\%2520et\%2520al. pdf>. Doi: 10.5897/AJB10.677.

FLORENCIO, C., COURI, S., FARINAS, C. S. Correlation between agar plate screening and solid-state fermentation for the prediction of cellulase production by Trichoderma strains. Enzyme Research, v. 2012, p.1-7, 2012. Disponível em:< https://www.hindawi.com/journals/er/2012/793708/>. Doi: 10.1155/2012/793708.

GEBREYOHANNES, G.; MOGES, F.; SAHILE, S.; RAJA, N. Isolation and characterization of potential antibiotic producing actinomycetes from water and sediments of Lake Tana, Ethiopia. Asian Pacific Journal of Tropical Biomedicine, v.3, n. 6, p. 426-435, 2013. Disponível em:http://dx.doi.org/10.1016\%2FS22211691(13)60092-1>. Doi: 10.1016\%2FS2221-1691(13)60092-1.

GEBREYOHANNES, G. Isolation and optimization of amylase producing bacteria and actinomycetes from soil samples of Maraki and Tewedros campus, University of Gondar, North West Ethiopia. African Journal of Microbiology Research, v.9, n.31, p. 1877-1882, 2015. $\quad$ Disponível em:< http://www.academicjournals.org/journal/AJMR/article-abstract/B02D16654833>. Doi:10.5897/AJMR2014.7027.

GORLACH-LIRA, K.; COUTINHO, H. D.M. Population Dynamics and Extracellular Enzymes Activity of Mesophilic and Thermophilic Bacteria Isolated from Semi-arid Soil of Northeastern Brazil. Brazilian Journal of Microbiology, v.38, n.1, p. 135141, 2007. Disponível em:< http://dx.doi.org/10.1590/S1517-83822007000100028>. Doi:10.1590/S1517-83822007000100028.

GUPTA, P.; SAMANT, K.; SAHU, A. Isolation of Cellulose-Degrading Bacteria and Determination of Their Cellulolytic Potential. International Journal of Microbiology, v. 2012, n. 2012, p. 1-5, 2011. Disponível em:< http://dx.doi.org/10.1155/2012/578925>. Doi: doi:10.1155/2012/578925.

HENG, J. L. S.; HAMZAH, H. Biological active compounds from actinomycetes isolated from soil of Langkawi Island, Malaysia. African Journal of Biotechnology, v.13, n.49, p. 4523-4528, 2014. Disponível em:< 
www.academicjournals.org/journal/AJB/article-full-text.../EAFC72D48940>.

Doi: 10.5897/AJB09.749.

IPECE - Instituto de pesquisa e estratégica econômica do Ceará. Perfil básico municipal-Marco $2015 . \quad$ Disponível em:< http://www.ipece.ce.gov.br/perfil_basico_municipal/2015/Marco.pdf>. Acesso em 14/09/2016.

IRFAN, M., ASMA, S., QURATULAIN, S., MUHAMMAD, N. Isolation and screening of cellulolytic bacteria from soil and optimization of celulase production and activity. Turkish Journal of Biochemistry, v.37, p. 287-293, 2012. Disponível em:< http://www.journalagent.com/tjb/pdfs/TJB-09709-IRFAN.pdf>.

Doi:10.5505/jtb.2012.09709.

KAFILZADEH, F; DEHDARI, F. Amylase activity of aquatic actinomycetes isolated from the sediments of mangrove forests in south of Iran. Egyptian Journal of Aquatic Research, v.41, p. 197-201, 2015. Disponível em:< http://dx.doi.org/10.1016/j.ejar.2015.04.003>. Doi: 10.1016/j.ejar.2015.04.003

KÖBERL, M.; MU"LLER, H.; RAMADAN, E. M.; BERG, G.Desert Farming Benefits from Microbial Potential in Arid Soils and Promotes Diversity and Plant Health. PLoS ONE, v. 6, n. 9, p. 1-9, 2011. Disponível em:< http://dx.doi.org/10.1371/journal.pone.0024452>. Doi:10.1371/journal.pone.0024452

KUZYAKOV, Y.; BLAGOTSKAYA, E. Microbial hotspots and hot moments in soil: Concept \& review. Soil Biology \& Biochemistry, v. 83, p. 184-199, 2015. Disponível em:< http://dx.doi.org/10.1016/j.soilbio.2015.01.025>. Doi: 10.1016/j.soilbio.2015.01.025.

LEBLANC, J. C.; GONÇALVES, E. R.; MONH, W.W. Global response to desiccation stress in the soil actinomycete Rhodococcus jostii RHA1. Applied and Environmental Microbiology, v.74, p. 2627-2636, 2008. Disponível em:< http://www.ncbi.nlm.nih.gov/pubmed/18326668>. Doi:10.1128/AEM.02711-07.

LEARN-HAN, L.; YOKE-KQUEM, C.; SHIRAN, M. S.; VUI-LING, C. M. W.; NURULSYAKIMA, A. M.; SON, R.; ANDRADE, H. M. Identification of actinomycete communities in Antarctic soil from Barrientos Island using PCR-denaturing gradient gel electrophoresis. Genetics and Molecular Research, v.11, n.1, p. 277-291, 2012. Disponível em:< http://dx.doi.org/10.4238/2012.February.8.3>. doi: 10.4238/2012.February.8.3.

MABROUK, M. I.; SALEH, N. M. Molecular Identification and Characterization of Antimicrobial Active actinomycetes strains from Some Egyptian Soils. AmericanEurasian Journal Agriculture \& Environment Scince, v.14, p.954-963, 2014. Disponível em:< http://idosi.org/aejaes/jaes14(10)14/1.pdf>. $\quad$ Doi: 10.5829/idosi.aejaes.2014.14.10.8641.

MAKOI, J. H. J. R.; NDAKIDEMI, P.A. Selected soil enzymes: Examples of their potential roles in the ecosystem. African Journal of Biotechnology, v.7, n.3, p. 
181-191, 2008. Disponível em:< www.academicjournals.org/.../article1379766462_ Makoi\%20and\%20Ndakidemi.pdf>. Doi: 10.5897/AJB07.590.

MANSOUR, S. R.; ABDEL-AZEEM, A. M.; ABO-DERAZ, S. S. S. A new record of Actinobacteria isolated from soil in Jerusalem and their enzymatic potential. F1000Research, v. 4, p. 1-10, 2015. Disponível em:<http://dx.doi.org/10.12688/f1000research.3257.>. Doi: 10.12688/f1000research.3257.

MINOTTO, E., MILAGRE, L.P., OLIVEIRA, M.T., VAN DER SAND, S.T.. Enzyme characterization of endophytic actinobacteria isolated from tomato plants. Journal of Advenced Scientific Research, v. 5, p. 16-23, 2014. Disponível em:< http://www.sciensage.info/journal/1401240027JASR_0302141.pdf>.

MOHAMMADIPANAH, F.; WINK, J. Actinobacteria from Arid and Desert Habitats: Diversity and Biological Activity. Frontiers in Microbiology, v.6, n. 1541, p. 1-10, 2016. Disponível em:< http://dx.doi.org/10.3389/fmicb.2015.01541>. Doi: 10.3389/fmicb.2015.01541.

MOHANTA, Y. K. Isolation of cellulose-degrading actinomycetes and evaluation of their cellulolytic potential. Bioengineering and Bioscience, v.2, n.1, p. 1-5, 2014. Disponível em:< http://www.hrpub.org/journals/article_info.php?aid=1121>. Doi: 10.13189/bb.2014.020101.

PRIYADHARSINI, P.; DHANASEKAREN, D. Diversity of soil allelopathic actinobacteria in Tiruchirappalli district, Tamilnadu, India. Journal of the Saudi Society of Agricultural Sciences, v.14, p. 54-60, 2015. Disponível em:<h ttp://dx.doi.org/10.1016/j.jssas.2013.07.001>. DOI: 10.1016/j.jssas.2013.07.001.

SAKURE, S.; LIMBORE, A.; ZALAKE, M.; JAIGUDE, S. Isolation and characterization of Actinomycetes from rhizosphere soil of different plants for antiphytopathogenic activity and stress tolerance. International Journal of Current Microbiology and Applied Sciences, v.2, p. 379-387, 2015. Disponível em:< http://www.ijcmas.com/special/2/Sunita\%20Sakure,\%20et\%20al.pdf>.

SALAHUDDIN, K.; PRASAD, R.; KUMAR, S.; VISAVADIA, M. D. Isolation of soil thermophilic strains of actinomycetes for the production of $\alpha$-amylase. African Journal of Biotechnnology, v.10, n.77, p. 17831-17836, 2011. Disponível em:< http://dx.doi.org/10.5897/AJB11.2194 >. DOI: 10.5897/AJB11.2194

SHARMA, M Actinomycetes: source, identification, and their applications. International Journal of Current Microbiology and Applied Sciences, v.3, n.2, p. 1827-1834, 2014. Disponível em: < http://www.ijcmas.com/vol-32/Mukesh\%20Sharma.pdf>.

SILVA, M. S.; SALES, A. N.; MAGALHÁES-GUEDES, K. T.; DIAS, D. R.; SCHAN, R. F. Brazilian cerrado soil actinobacteria ecology. BioMed Research International, v. 2013, p. 1-10, 2012. Disponível em:< http://dx.doi.org/10.1155/2013/503805>. Doi: $10.1155 / 2013 / 503805$. 
SILVA, V. M. A; LIMA, J. V. L.; GONDIM, P. M.; MARTINS, C. M.; MARTINS, S. C. $S$. Effect of irrigation and type of cultivation on richness and diversity of chromogenic actinobacteria of soil from Ceará semiarid region. Enciclopédia Biosfera, v.11, n.22, p. 2965-2979, 2015a. Disponível em:< http://dx.doi.org/10.18677/Enciclopedia_Biosfera_2015_016>. Doi: 10.18677/Encicopedia_Biosfera_2015_016

SILVA, V. M. A.; BRITO, F. A. E.; RAMOS, K. A.; SILVA, R. M.; MARTINS, C. M.; MARTINS, S. C. S. Atividade enzimática de actinobactérias do semiárido. Revista Brasileira de Geografia Física, v. 8, p. 560-572, 2015b. Disponível em:< http://www.revista.ufpe.br/rbgfe/index.php/revista/article/viewArticle/1470>.

SUBRAMAN, R.; AALBERSBERG, W. Marine actinomycetes: An ongoing source of novel bioactive metabolites. Microbiological Research, v. 167, p. 571-580, 2012. Disponível em:< http://dx.doi.org/10.1016/j.micres.2012.06.005>. Doi: 10.1016/j.micres.2012.06.005.

VAN HOP, D.; SAKIYAMA, Y.; BINH, C. T. T.; OTOGURO, M.; HANG, D. T.; MIYADOH, S.; LOUNG, D. T.; ANDO, K. Taxonomic and ecological studies of actinomycetes from Vietnam: isolation and genus-level diversity. The Journal of Antibiotics, v.64, p. 599-606, 2011. Disponível em:< http://www.nature.com/ja/journal/v64/n9/pdf/ja201140a.pdf>.Doi: 10.1038/já.2011.40. 